\title{
Not Identified
}

National Cancer Institute

\section{Source}

National Cancer Institute. Not Identified. NCI Thesaurus. Code C48661.

The finding is not present, but a value of 'none' cannot be unequivocally established absence in the current context. 